\title{
Defining quality during ex vivo lung perfusion: The University of Maryland experience
}

\author{
Pablo G. Sanchez, MD, PhD, Keshava Rajagopal, MD, PhD, Si M. Pham, MD, and Bartley P. Griffith, MD, \\ Baltimore, Md
}

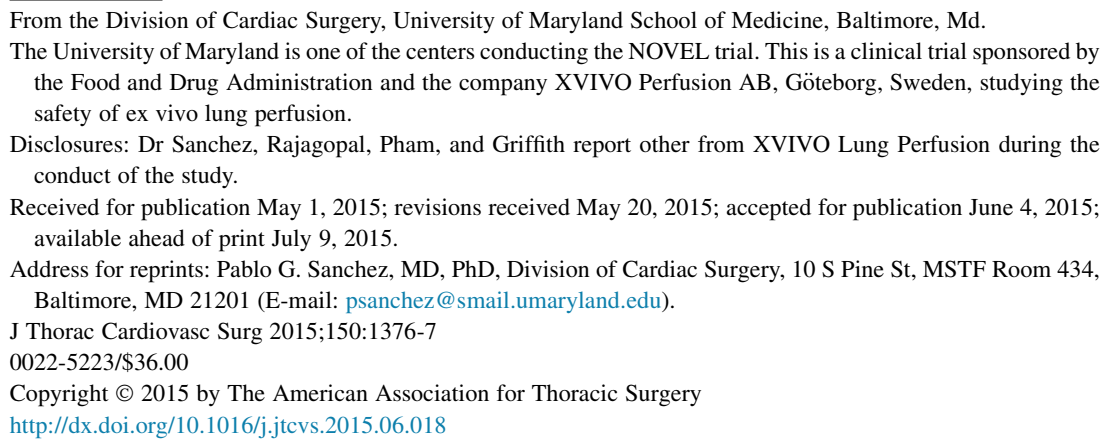

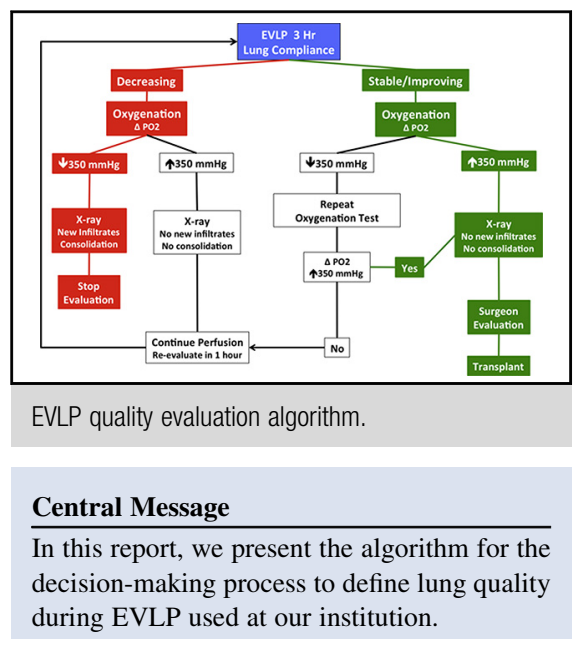

See Editorial Commentary page 1378.
Data from single-center and multicenter studies have encouraged lung transplant centers to screen the unused donor pool with ex vivo lung perfusion (EVLP). Reports have concentrated on demonstrating safety. Nevertheless, descriptions of the decision-making process to judge lungs suitable for transplantation after EVLP are currently lacking. As the use of EVLP increases, descriptions of this process will prove necessary to improve conversion rates while maintaining safety.

Two clinical trials have described the variables that investigators should consider as the basis for deciding whether to use lungs. ${ }^{1,2}$ In our experience, as one of the centers for the Normothermic Ex Vivo Lung Perfusion (NOVEL) trial, EVLP variables cannot be weighed equally, and in many cases clinical judgment prevails. In addition, lung compliance and oxygenation, the 2 most relevant variables used to define quality, depend highly on the level of lung parenchyma recruitment. In this report, we describe the systematic approach followed at our institution to interpret data provided by the EVLP system.

Traditionally, when evaluating lung donor quality gas exchange is considered the most important single parameter to gauge lung quality. The value of $\mathrm{Po}_{2}$ in EVLP with an acellular perfusate has been questioned on the grounds that only a few molecules of oxygen are required to increase it significantly in plasmalike solutions. In addition, experimental data in large animals demonstrate that lung compliance deteriorates earlier than does $\mathrm{Po}_{2}$ during the evolution of acute lung injury. ${ }^{3}$ This is not surprising, because loss of capillary barrier function, with its consequent accumulation of interstitial and intra-alveolar fluid typically, precedes a fall in systemic oxygen saturation.

Staub and colleagues ${ }^{4}$ described the earliest manifestation of pulmonary edema as the appearance of liquid in the interstitial space around the extra-alveolar airways and vessels. Recently, Lowe and colleagues ${ }^{5}$ demonstrated that extra-alveolar vascular cuffs in normal rat lungs decrease lung compliance even in the setting of normal $\mathrm{Po}_{2}$.

\section{MATERIALS AND METHODS}

On the basis of these observations, we designed an EVLP evaluation algorithm. Our algorithm is centered on the finding that lung compliance deteriorates earlier than any other parameter in EVLP, making oxygenation secondary to the compliance trend (Figure 1).

In our practice, we decide not to transplant by closely monitoring the deterioration in lung compliance; in most cases, oxygenation follows the compliance trend. In some cases in which compliance falls but the oxygenation is above a difference between $\mathrm{Po}_{2}$ in the left atrium and $\mathrm{Po}_{2}$ in the pulmonary artery $\left(\Delta \mathrm{Po}_{2}\right)$ of at least $350 \mathrm{~mm} \mathrm{Hg}$, we continue perfusion for 1 extra hour. In this additional hour, we generally see a decrease in oxygenation.

We decide to transplant when the lung compliance is stable or improving. We complement this decision with a $\Delta \mathrm{Po}_{2}$ of at least $350 \mathrm{~mm} \mathrm{Hg}$ and the absence of significant new infiltrates or consolidations on the chest radiograph. We perform chest radiography of the lungs at hour 1 and 3. In cases in which the lung compliance is stable or improving but the $\Delta \mathrm{Po}_{2}$ is less than $350 \mathrm{~mm} \mathrm{Hg}$, we repeat the recruitment maneuver and recheck the gas values. Errors on collection of the perfusate can lead to low measured $\mathrm{PO}_{2}$. If the $\Delta \mathrm{Po}_{2}$ continues to be less than $350 \mathrm{~mm} \mathrm{Hg}$, we perfuse for an extra hour and revaluate.

In some cases where 2 lungs are being evaluated and only 1 has poor quality, the compliance can be stable despite a $\Delta \mathrm{PO}_{2}$ of less than $350 \mathrm{~mm} \mathrm{Hg}$. In such cases we measure selective vein gas values to evaluate oxygenation separately for each lung. If the $\Delta \mathrm{Po}_{2}$ is at least $350 \mathrm{~mm} \mathrm{Hg}$ for the better lung, we normally proceed with a single-lung transplant.

Other variables, such as pulmonary vascular resistance, pulmonary arterial pressure, and left atrial pressure, have not consistently show, differences between lungs judged "suitable" versus "not suitable," and we do not use them as part of our decision process (Table 1). Independent of 


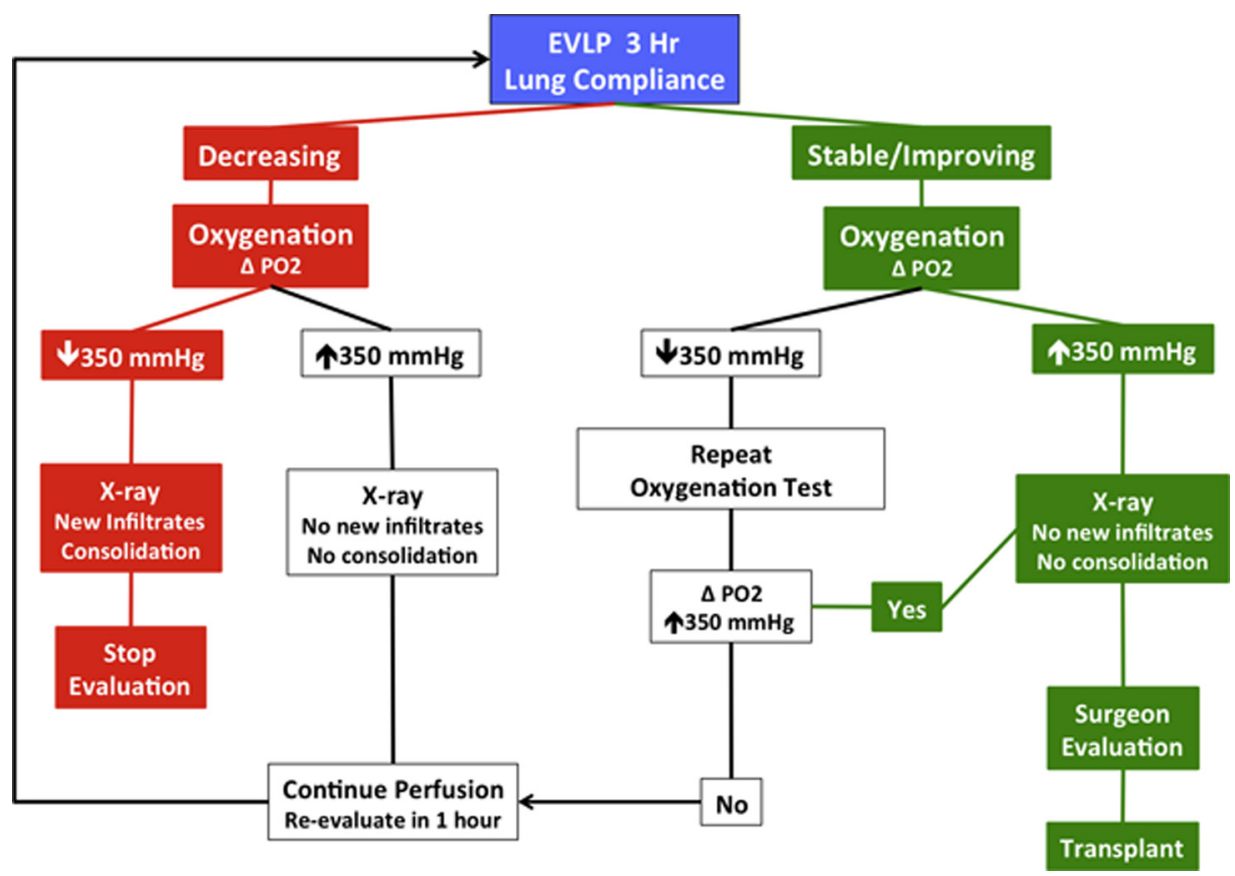

FIGURE 1. Algorithm for the evaluation of lung quality in ex vivo lung perfusion $(E V L P) . \Delta \mathrm{PO}_{2}$, Difference between $\mathrm{Po}_{2}$ in the left atrium and $\mathrm{Po}_{2}$ in the pulmonary artery.

TABLE 1. Comparison of physiologic variables for ex vivo lung perfusion transplanted and ex vivo lung perfusion nontransplanted lungs

\begin{tabular}{|c|c|c|c|c|c|c|}
\hline & \multicolumn{3}{|c|}{ EVLP transplanted $(n=11)$} & \multicolumn{3}{|c|}{ EVLP nontransplanted $(n=6)$} \\
\hline & Hour 2 & Hour 3 & $P$ value & Hour 2 & Hour 3 & $P$ value \\
\hline PAP (mm Hg) & $7.5 \pm 2.4$ & $7 \pm 2.6$ & .9 & $5.6 \pm 1.7$ & $6.3 \pm 0.9$ & .5 \\
\hline $\mathrm{LAP}(\mathrm{mm} \mathrm{Hg})$ & $3.3 \pm 0.5$ & $3.3 \pm 0.8$ & .5 & $2.8 \pm 0.8$ & $3.7 \pm 0.5$ & .75 \\
\hline PVR (dyne $\cdot \mathrm{s} \cdot \mathrm{cm}^{-5}$ ) & $172 \pm 108$ & $156 \pm 100$ & .2 & $136 \pm 55$ & $134 \pm 75$ & .5 \\
\hline$\Delta \mathrm{Po}_{2}(\mathrm{~mm} \mathrm{Hg})$ & $369 \pm 21$ & $416 \pm 47$ & .01 & $312 \pm 81$ & $233 \pm 94 *$ & .4 \\
\hline Peak airway pressure $\left(\mathrm{cm} \mathrm{H}_{2} \mathrm{O}\right)$ & $11.9 \pm 3.1$ & $11.2 \pm 1.6$ & .2 & $12.5 \pm 2.2$ & $12.1 \pm 1.8$ & .5 \\
\hline Mean airway pressure $\left(\mathrm{cm} \mathrm{H}_{2} \mathrm{O}\right)$ & $6.7 \pm 0.9$ & $6.5 \pm 0.5$ & .2 & $6.8 \pm 0.6$ & $6.9 \pm 0.9$ & .7 \\
\hline Static lung compliance $\left(\mathrm{mL} \cdot \mathrm{cm} \mathrm{H}_{2} \mathrm{O}\right)$ & $97.5 \pm 39.1$ & $104.4 \pm 35.6$ & .2 & $77.4 \pm 30.2$ & $69.5 \pm 21.9^{*}$ & .3 \\
\hline
\end{tabular}

Values expressed as mean \pm SD. PAP, Pulmonary arterial pressure; $L A P$, left atrial pressure; $P V R$, pulmonary vascular resistance; $\Delta \mathrm{PO}_{2}$, difference between $\mathrm{Po}_{2}$ in the left atrium and $\mathrm{PO}_{2}$ in the pulmonary artery; EVLP, ex vivo lung perfusion; $\mathrm{H}_{2} O$, water. $* P<.05$ between EVLP nontransplanted and EVLP transplanted lungs at hour 3.

the data provided by the EVLP system, the transplant surgeon's visual and manual evaluation of the lungs remains essential. Nevertheless, in our experience no lung was rejected solely on the basis of the surgeon's evaluation. All rejected lungs had decreasing lung compliance and oxygenation, which correlated with increased opacities on the radiograph. These observations correlated with decreased lung ventilatory excursion, mainly of the lower lobes, and increased bogginess during manual inspection.

\section{RESULTS}

To the date, we have evaluated 17 donor lungs with EVLP and transplanted 11 , for a $65 \%$ conversion rate. All transplanted lungs after EVLP in this experience performed well. None of these patients had signs severe primary graft dysfunction at 72 hours.

\section{DISCUSSION}

Evaluation of lungs with EVLP is an evolving experience, and as new methods of measuring lung performance are developed, refinements to our lung management algorithm and decision tree should be incorporated. We believe that in its current format our assessment algorithm is simple, and evidence to date supports our contention that it is associated with safe "go/no-go" decisions when applied to those clinical scenarios that we have encountered to date.

\section{References}

1. Cypel M, Yeung JC, Machuca T, Chen M, Singer LG, Yasufuku K, et al. Experience with the first 50 ex vivo lung perfusions in clinical transplantation. J Thorac Cardiovasc Surg. 2012;144:1200-6.

2. Sanchez PG, Davis RD, D'Ovidio F, Cantu E, Weyant M, Camp P, et al. The NOVEL Lung Trial one-year outcomes [abstract]. J Heart Lung Transplant. 2014;33:S71-2.

3. Sanchez PG, Bittle GJ, Burdorf L, Pierson RN III, Griffith BP. State of art: clinical ex vivo lung perfusion: rationale, current status, and future directions. J Heart Lung Transplant. 2012;31:339-48.

4. Staub NC, Nagano H, Pearce ML. Pulmonary edema in dogs, especially the sequence of fluid accumulation in lungs. J Appl Physiol. 1967;22:227-40.

5. Lowe K, Alvarez DF, King JA, Stevens T. Perivascular fluid cuffs decrease lung compliance by increasing tissue resistance. Crit Care Med. 2010;38:1458-66. 